УДК 94(47).084

Л. Н. Величко, К. Р. Амбарцумян

\title{
АРМЯНО-ГРУЗИНСКИЙ ТЕРРИТОРИАЛЬНЫЙ ВОПРОС И ОСОБЕННОСТИ НАЦИОНАЛЬНО- ГОСУДАРСТВЕННОГО СТРОИТЕЛЬСТВА В ЗАКАВКАЗЬЕ (1918 г.)
}

В статье приводится анализ напряжённой и нестабильной политической ситуации в Закавказье в период 1918 г., когда Грузия, Армения и Азербайджан заявили о своей независимости и приступили к территориальному оформлению своих границ, окончательно похоронив идею Закавказской Конфедерации. Автор сосредотачивается на характеристике общественно-политических позиций в определении границ Армении и Грузии, сложившихся в условиях продолжающейся Первой мировой войны. В статье исследуются не только убеждения правящих кругов, но также отражено видение ситуации публицистами, стремящимися оказать влияние на широкие массы населения.

Источниковую базу исследования составили дипломатические документы, воспоминания политических деятелей, материалы периодической печати. Их анализ позволил определить позиции сторон в обозначении концептуальных позиций формирования границ независимых государств, показать причины территориальных претензий Армении и Грузии, роль государств Антанты и причины их неудач в разрешении этно-территориаль- ных противоречий, надолго определивших отношение к региону со стороны других государств.

Давая оценку приводимым фактам, авторы приходит к выводу, что, отдав абсолютный приоритет вопросам территориального раэмежевания при формировании собственной государственности, армянская и грузинская сторона в большей степени полагалась на арбитраж стран Антанты, не стремясь к самостоятельному решению вопроса. Идея создания Закавказской конфедерации, могущей окаэаться наиболее жиэнеспособным политическим формированием в условиях сложившейся геополитической ситуации, уступила место амбициям национальных политических элит, не справившихся с желанием во что бы то ни стало увеличить свои масштабы за счёт территорий соседей и определило за ними репутацию «недоговороспособных», что стало одной из причин потери так и не оформившейся государственности.

Ключевые слова: Закавказская конфедерация Антанта, армяно-грузинская война 1918 г., газета «Грузия», Н. Жордания, З. Авалов.

L. Velichko, K. Ambartsumyan

\section{THE ARMENIAN-GEORGIAN TERRITORIAL ISSUE AND THE PECULIARITIES OF NATION-STATE BUILDING IN THE TRANSCAUCASUS (1918)}

The article provides the analysis of the tense and unstable political situation in Transcaucasia during the period of 1918, when Georgia, Armenia and Azerbaijan declared their independence and began to territorialize their borders, finally burying the idea of the Transcaucasian Confederation. The author focuses on the characterization of socio-political positions in defining the borders of Armenia and Georgia that have developed in the context of the ongoing World War I. The article explores not only the beliefs of the ruling circles, but also reflects the vision of the situation by publicists who seek to influence the broad masses of the population

The source for study are different historical documents: diplomatic documents, memoirs of politicians, and periodical materials. Their analysis made it possible to determine the positions of the parties in designating the conceptual positions of the formation of the borders of independent states, to show the reasons for the territorial claims of Armenia and Georgia, the role of the Entente states and the reasons for their failures in resolving ethno-territorial contradictions, which for a long time determined the attitude of other states to the region.

Assessing the facts cited, the authors conclude that having given absolute priority to the issues of territorial delimitation in the formation of their own statehood, the Armenian and Georgian sides relied more on the arbitration of the Entente countries, not trying to independently resolve the issue. The idea of creating a Transcaucasian Confederation, which could turn out to be the most viable political formation in the current geopolitical situation, gave way to the ambitions of national political elites, who could not cope with the desire to increase their scale at any cost at the expense of the territories of their neighbors and determined their reputation as "unsupportable", which was one of the reasons for the loss of statehood that did not take shape.

Key words: Transcaucasian Confederation, Entente, Armenian-Georgian War of 1918, the newspaper Georgia, N. Zhordania, Z. Avalov.

\footnotetext{
${ }^{1}$ Статья выполнена в рамках проекта «Большой Кавказ в контексте внешней политики России (1917-1922 гг.)», поддержанного РФФИ (18-09-00444).
} 
Вопрос о государственной самостоятельности регионов Закавказья не ставился в качестве политического требования национальными партиями вплоть до 1917 г. В частности, в Грузии, ни социал-демократы, ни примкнувшие к ним социал-федералисты не видели её политической независимости в ближайшей перспективе, выступая лишь за широкую автономию в составе Российского государства. Полную независимость для Грузии отстаивала группа последователей Ильи Чавчавадзе и традиций движения «Тергдалеулни». В июле 1917 г. они основали национал-демократическую партию, выдвинувшую лозунг политической самостоятельности Грузии. Но даже тогда призывы партии начать процесс отделения от России не имел широкой поддержки. Политические элиты Закавказья были настроены участвовать в выборах в Учредительное собрание и активно обсуждали кандидатуры делегатов [14, с. 158-160]. Октябрьские события 1917 г. и разгон большевиками Учредительного собрания в январе 1918 г. толкнули политические силы национальных окраин на организацию собственных органов управления. Ктому же, принятая большевиками 1ноября 1917 г «Декларация прав народов России», в которой провозглашалось право народа на самоопределение, вплоть до отделения, актуализировала процесс создания собственной государственности, в том числе и для закавказских народов.

Уже ноябре 1917 г. состоялся созыв Первого Национального всегрузинского съезда, инициаторами создания которого выступили Грузинское дворянское собрание и всепартийный Совет. Съезд учредил 22 ноября Национальный Совет, в состав которого вошли социал-демократы, национал-демократы, социал-федералисты. Именно Национальный совет взял на себя полномочия институционального оформления грузинского государственного и территориального управления. Фактически этот процесс шёл параллельно с намерением создать Закавказскую Федерацию на основе объединения Армении, Грузии и Азербайджана. Но эта попытка объединиться показала свою несостоятельность уже в марте 1918 г., когда после подписания большевиками Брестского мира, по которому к Турции переходили Карс, Ардаган и Батуми, по всему Закавказью прокатилась волна антибольшевистских и одновременно национально-патриотических настроений. Основным требованием недовольных стало провозглашение независимости от Советской России Закавказья [15, с.128-129]. А. И. Хатисов, отмечал, что объявление независимости было вынужденным шагом, поскольку только так можно было начать переговорный процесс с наступающими турками и предотвратить захват ими Закавказья. Но и в этих условиях и армянские представители Сейма и грузинское меньшевистское руководство во главе с Н. Жордания были против провозглашения независимости Закавказья, полагая, что именно в этом случае оно станет лёгкой добычей для турок [4, с. 83-85].

Военные успехи Порты на Кавказе и их поддержка со стороны мусавитистов Азербайджана привели к тому, что 26 мая была провозглашена независимость Грузии, 28 мая независимыми стали Армения и Азербайджан, а 4 июня 1918 г. был подписан Батумский мирный договор между Османской империей и тремя самопровозглашёнными государствами. По этому договору, Грузия и Армения фактически были разделены территориями оккупированными войсками Османской империи: Армения состояла из Эриванского (Ереванского), Эчмиадзинского и Ново-Баязетского уездов, за Грузией, заключившей сепаратное соглашение с Германией, сохранялась Кутаисская и часть Тифлисской губернии (без аннексированных Портой Ахалцыхского и Ахалкалакского уездов, а Александропольский уезд, оказался аннексирован и частично оккупирован Турцией. Кроме того, стратегические задачи Турции, оказывающей помощь независимому Азербайджану в борьбе с большевиками, требовали контроля над частью Лорийского участка Борчалинского уезда Тифлисской губернии, примыкающего к шоссейной дороге, по которой перемещались турецкие войска. Грузия, объявившая о своём нейтралитете, сблизилась с Германией, которая стала гарантом того, что турецкие войска не вторгнутся в Грузию, разместила в Тифлисе свой гарнизон с согласия главы государства Н. Жордании, видевшего в немецком присутствии защиту грузинского суверенитета.

Изменившееся к октябрю 1918 г. положение на фронтах, вело к тому, что уже в начале месяца турецкое командование фактически начало эвакуацию войск из аннексированных на Кавказе территорий и создавало ситуацию «неразберихи» в их передаче под контроль Армении или Грузии, что неизбежно порождало конфликты между последними. Эти события стали основой для очередного витка проблем, связанных теперь с определением государственных границ новых национальных образований.

«Турецкий фрактор» в провоцировании конфликта между Грузией и Арменией отмечен фактом того, что 25 октября 1918 г. поверенный в делах Армении А. Джамалян, обращаясь к министру внутренних дел Грузии Н. Рамишвили, писал, что Г. Гварджаладзе заместитель министра иностранных дел республики, заявил о том, что представитель Турции в Грузии Керим-паша предложил грузинам занять Лорийский район, из которого уходят турки, аналогичное же предложение было сделано армянской стороне от имени Мамед Али паши. Из этого следует, что решение вопроса о спорной территории должны решить сами армяне и грузины «по обоюдному согласию» - отмечал автор статьи в газете «Грузия» [8].

По согласованию с турецким командованием вооружённые силы Армении взяли под контроль территории Эриванской губернии и вошли в Борчалинский уезд Тифлисской губернии к югу от Каменки, заняли железнодорожный разъезд Кобери, находившийся на грузинской стороне. Позиции сторон заключались в следующем: Армения заявляла о своих претензиях на Ахалкалакский и более половины Борчалинского уезда, грузинская 
сторона настаивала на том, что юго-восточная граница Тифлисской губернии не подлежит ревизии, при этом грузинские власти рассматривали возможность включения в состав Грузии частей Казахского уезда Елисаветпольской губернии и Александропольского уезда Эриванской губернии. Эти обстоятельства перевели решение о государственной границе между Грузией и Арменией в военно-политическую плоскость [3]

Параллельно с этим, вопрос о том, на каких основаниях и принципах должно проходить территориальное оформление Армении, Грузии и Азербайджана стал широко обсуждаться общественностью на страницах периодической печати. Одним из таких органов, претендующих на освещение «национального» взгляда относительно государственно-территориальных границ Грузии стала ежедневная политическая и литературная газета «Грузия», которую большинство исследователей идентифицируют как печатный орган национал-демократической партии Грузии. Издаваться «Грузия» начала ещё в 1915 г., но «территориальный вопрос» стал постоянной тематикой газеты с 1918 г. Примечательно, что издание выходило и на русском языке, охватывая практически полностью весь национальный состав читающего населения. Особенно интересными являются «политические заметки» публициста, печатающегося под именем К. П. Туманов, раскрывающего концептуальные позиции оформления территориальных границ кавказских государств, разделяемые националистически настроенными кругами общественности Грузии.

Во-первых, резкой критике подвергался «принцип реального расселения», который во главу угла территориального размежевания ставила армянская сторона. Его суть сводилась к тому, что границы следует проводить, опираясь на национальный состав населения. В напечатанной в «Грузии» выдержки из ежедневной газеты «Ашхатавор», издававшейся в Тифлисе с 1917 г. и являющейся печатным органом армянской партии Дашнакцутюн, читателям предлагалось рассмотреть позицию противоположной стороны: «Мы полагаем, что патриотическая радость грузинских социал-демократов по поводу воссоединения Грузии должна быть отнесена только к занятию Ахалцихского уезда. Что касается Ахалкалакскаго уезда, то вопрос надо считать в лучшем случае пока открытым для грузинских меньшевиков.. так как Армения имеет более основательные и неоспоримые претензии к Ахалкалакскому уезду». Вопрос о территориальной принадлежности этого уезда, а также вопрос о Лори, части Борчолинского уезда, которые Армения считает своими, следует решать путём демократического референдума населения, проживающего на этих землях [10].

К. П. Туманов пишет: «Нам приходилось указывать, что в продолжении веков территория расселения армянского народа имеет тенденцию поэтапно продвигаться к северу, при чем на юге армяне постепенно теряют свою территорию, завоёвывая мирным, но не всегда естественным путём, новые территории на севере. В результате происходит ослабление армянского элемента в тех областях Турции, которые называют Арменией и увеличение армянского населения в пределах Кавказа. Каждая война с Турцией дарила Кавказу сотни тысяч армянских беженцев, которые оставались жить у нас, причем, по статистическим подсчётам, около миллиона нынешних армян Закавказья это беженцы и их потомки, т.е. не уроженцы Кавказа. В результате армянам пришлось в своих требованиях восстановления турецкой Армении оковывать эти требования не на этнографическом принципе, который - за выселением армянского населения с родины - для них уже не благоприятен, а на принципе историческом и одновременно основывать свои требования в пределах Кавказа на принципе этнографическом, на принципе реального расселения, совершенно отрицая какие бы то ни было исторические права за соседними народами. Этот принцип реального расселения будут выдвигать армяне, очевидно, и на предстоящей конференции, причём, если судить по статьям газеты «Азербайджан», на этом же принципе будут настаивать представители мусульманского населения Восточного Закавказья [9].

На страницах «Грузии» за период с июля по ноябрь 1918 г. активно публиковались статьи, в которых обсуждалась проблема расселения армянского населения на территориях, оспариваемых Грузией и Арменией друг у друга. Всё тот же К. П. Туманов значительное внимание уделял анализу переселенческой политики российского правительства до 1917 г., указывая, что немалую роль в компактном проживании армянского населения на грузинских землях сыграла Россия, которая после 1828 г. способствовала оттоку из этих мест грузин-мусульман, переезжавших на отторгнутых у Османской империи территории. Кроме того, по его словам, не стоит доверять и переписи населения [1897г.], в которой грузины-католики были причислены к армянам-католикам «В результате подобной статистики получилось выгодное для армян процентное соотношение их к прочим народам на бумаге, а это, в свою очередь, привело к требованию включения Ахалцихского уезда в пределы Армении». Кроме того, отмечалась активная деятельность «армянского лобби» при русском императорском дворе, которое способствовало расселению армян на кавказских территориях, занятых грузинами и «татарами» Азербайджана [10].

Второй вопрос, поднятый в связи с обретением государственности - наличие национального центра. И здесь у редакции и авторов статей «Грузии» нет сомнений по поводу того, что армянский народ не имеет такого культурно-национального центра в пределах Кавказа. «Культурные силь армянского народа тяготели к Тифлису и к Баку, в пределах армянской территории, могущей стать основой самостоятельного государства, они такой основы не находили и «г. Эривань, ставшей новой столицей армянского государства на Кавказе, также беден культурными силами и также лишён национально-культурных учреждений армянского 
народа, как любой уездный город той или иной кавказской губернии» [10]. По мнению публицистов, при определении территориальных границ кавказских государств должно быть положено три принципа: экономический, этнографический и исторический. «Фактически достаточную для образования самостоятельного государства территорию имеют лишь грузины и азербайджанцы, которые живут сплошными массами в пределах своих государств. Форма расселения армянского народа у нас к сожалению, даёт основание для предъявления многочисленных споров, и армянская территория может быть создана лишь в том случай если все споры без исключения будут разрешены в пользу армян, при чем будет упущено из виду и начало экономическое и начало историческое, и, если не будет опрошено население соответствующих провинций. При этом во всех случаях будут нарушены интересы прочих национальностей, живущих в этих провинциях" [11].

Парламентом и правительством Грузии поддерживалась идея выработки «рабочего проекта» разграничения территорий, который должен был быть представлен на Всемирном конгрессе (Парижской мирной конференции), предварительно составленном на Кавказской конференции, открытие которой намечалось на 3 ноября 1918 г Её созыв планировался при инициативе грузинской стороны, приглашавшей на конференцию как представителей Азербайджана, так представителей Армении и Союз горских народов Северного Кавказа. В телеграмме от 27 октября 1918 г в адрес правительства республики Армения, подписанной министром иностранных дел республики Грузия Н. Рамишвили отмечалось, что одной из целей собрания, является «разрешение всех вопросов, не исключая и споры о границах по соглашению заинтересованных государств, а при отсутствии такого соглашения - при посредничестве арбитража» $[1$, л. 10]. Однако, открытие конференции не состоялось по причине отказа армянской делегации участвовать в ней. Армянская сторона требовала проявления необходимого в таких случаях дипломатического этикета в отношении суверенного государства и его руководства. В газете партии Дашнакцутюн «Занг», выходившей в Эривани, с возмущением отмечалось, что тон приглашения сравним с обращением к вассалам, а не предложение диалога «равному государству». Грузинское меньшевистское правительство «не приняло во внимание прав других народов и пренебрегло их самолюбием» $[6$, с. 52] Это признавал и Зураб Авалов (Авалишвили), исполнявший обязанности советника по иностранным делам Грузинского правительства в Лондоне в 1918 г., отмечая, что тон «пригласительной ноты, несколько напоминало циркуляр по министерству внутренних дел» [2, с. 167].

Однако, не амбиции политических лидеров препятствовали встречи, а ряд объективных причин. Во- первых, армянскую сторону смущало широкое представительство, включавшее делегатов из Азербайджана, а также Союз горцев. По словам А. И. Хатисова, министра иностранных дел Республики Армения, вызывало опасение влияния Баку на Тбилиси и «желание непосредственно с грузинами покончить спорный вопрос» $[1$, л. 17]. В случае обсуждения территориальных претензий в отношении Грузии или Азербайджана со стороны Армении, при возможном голосовании они могли бы объединиться против неё, к тому же, учитывая их влияние на Союз горцев, армянская делегация оказалась бы в абсолютном меньшинстве. Армянская сторона решение по созыву Закавказской Конференции и решение спорных территориальных вопросов на двустороннем уровне «не спешила разрешать, а выжидала начала Парижской конференции» [1, л. 17].

В газете «Ашхатавор", отмечалось, что представители армянского парламента отвергли приглашение, не видя цели конференции, полагая, что спорные территориальные вопросы между Грузией и Арменией должны были решаться усилиями представителей только этих государств, кроме того, в созыве конференции по инициативе грузинского правительства, армянская сторона видела проявление «националистической гегемонии» Грузии [12]

О том, что Армения затягивала возможность созыва конференции, свидетельствуют многочисленные ноты и телеграммы, которыми обменивались стороны в период с 3 ноября по 30 ноября 1918 г. При этом в ответах на предложения грузинской стороны, представители Армении настаивали на том, что решение территориального вопроса требует двустороннего принятия ещё до открытия конференции. 14 ноября 1918 г. министр иностранных дел Грузии Е. П. Гегичкори, обращаясь к дипломатическому представителю Грузии в Эрвани Мдивани писал: “Считая крайне необходимым участие на ней [Конференции] представителей Армении, мы решили сделать последнюю попытку для привлечения её представителей на Конференцию, которая не может быть отсрочена далее 20 ноября восьми часов вечера. Прошу передать армянскому правительству, что грузинское правительство идёт на встречу и просит армянское правительство прислать для этих целей своих представителей в кратчайшее время...в случае отсутствия их представителей нам придётся открыть конференцию без их участия» $[1$, л. 14]. Причину промедления следует видеть ещё и в том, что ноябрьские события 1918 г. в Германии лишали Грузию союзника и делали реальным вмешательство в её внутренние дела англичан, которых Армения видела своими патронами, рассчитывая на их дипломатическую и военную поддержку.

Затягивание участие в конференции армянской стороны можно объяснить ещё двумя фактами. Во-первых, представители армянского правительства возлагали большие надежды на помощь государств-победительниц в решении вопроса о границах и суверенитете Армении. На это у них были веские основания. Ряд западных лидеров, таких как премьер-министр Великобритании Дэвид Ллойд Джордж, Президент США Вудро Вильсон и премьер-министр Франции Жорж Клемансо 
пообещали армянам, что они будут освобождены от османского владычества в конце войны Ллойд Джордж изложил свои цели военного времени на профсоюзной конференции 5 января 1918 года, заявив: «Хотя мы не ставим под сомнение сохранение Турецкой империи на родине турецкого народа со столицей в Константинополе-проход между Средиземным и Черным морями интернационализируется и нейтрализуется-Аравия, Армения, Месопотамия, Сирия и Палестина, по нашему мнению, имеют право на признание их отдельных национальных условий).

Пункты 12 и 14 в «Четырнадцати пунктах» президента Вильсона, представленных Конгрессу в апреле 1918 г. и позиции Франции, выраженные в письме 14 июля 1918 года Жорж Клемансо в письме Богосу Нубар-Паше, сыну бывшего премьера Египта, армянского происхождения, которого ещё в 1912 г. католикос всех армян Геворг V Суренянц наделил полномочиями представлять интересы родного народа на конференциях по армянскому вопросу, говорил о готовности Франции решить армянский вопрос. Он заявил: «Я рад подтвердить Вам, что правительство республики, как и правительство Великобритании, не перестает относить армянский народ к тем народам, судьбу которых союзники намерены решить в соответствии с высшими законами гуманности и справедливости» [17].

Во-вторых, подписанное Османской империей 30 октября 1918 г. Мудросское перемирие с государствами Антанты, касалось и «армянского вопроса», в частности статьи $4,5,7,11,15$. Особенно следует отметить, что напрямую интересы Армении затрагивала статья 16, в которой указывалось пользование железными дорогами, ранее подконтрольными Порте с «учетом потребностей населения», а также оккупацию Батума союзными войсками и отмечалось, что оттоманская сторона не будет возражать против оккупации Баку союзниками. Это давало Армении возможность не быть оторванной от морских каналов связи, пусть и через посредничество союзников. В статье 24 констатировалось, что в случае беспорядков в шести армянских вилайетах союзники оставляют за собой право занять любую их часть [16]. Статьи виделись армянскому правительству фактом «особенного к Армении отношения» со стороны союзников [7, с. 68-69].

Как отмечал Зураб Авалов, «армянам показалось, хоть с самого начала это было неправильно и неосновательно, что Европа и Америка, «конференция» и вообще все решатели судеб отнесутся к ним совершенно по-особенному, и, что их вопрос не может быть смешиваемым, например, с грузинским» $[2$, с. 70$]$.

В этой напряжённой ситуации взаимного недоверия, при удачно складывающейся для Армении внешнеполитической обстановке, вдекабре 1918г начались грузино-армянские столкновения, вылившиеся в открытые военные действия. В этом конфликте Армения видела единственную возможность определить свою государственную границу с Грузией, а последняя видела в этом открытый акт агрессии и посягательства на её суверенные границы. В этих условиях «третьей» силой в конфликте оказались государства Антанты. Для Англии и Франции в 1918 г. Кавказ представлял собой южную территорию России, любой локальный конфликт на которой, мог повлечь за собой перестановку политических сил и появление ещё одного “уровня конфрликтности» в разрываемой гражданской войной стране. Проводя в Закавказье «политику двойных стандартов», английское и французское правительства стремились лавировать между поддержкой Добровольческой армии Деникина и вновь образованными правительствами национальных государств, с целью не допустить распространение здесь большевизма и национальных конфликтов [3]. По словам 3. Авалова в 1918-1919 гг. «англичан больше занимал вопрос о восстановлении порядка и единства России, чем поддержка независимости Грузии или Армении» [2, с. 162]. По этой причине точку в начавшейся войне поставил английский отряд во главе с капитаном Дугласом, а «примирение» сторон прошло при посредничестве английского генерала Райкрофта и начальника французской миссии на Кавказе полковника Шардиньи. 25 декабря Союзная комиссия в ультимативной форме потребовала от воюющих прекратить столкновения, развести войска, установив довоенный status quo и заверила, что «представители государств Грузии и Армении, будут в скором времени отправлены в Европу, где весь вопрос относительно границ будет решен Великими Державами», дав понять, что этот вопрос вышел на международный уровень.

Таким образом, вопрос о национальном строительстве в Закавказье не имевший до 1918 г., (краеугольного значения», актуализировался в связи с подписанием большевистским правительством Брест-Литовского договора, по существу приведшего к распаду Закавказской конфедерации и возникновению территориальных конфликтов. Начавшийся процесс суверенизации, сопровождался острыми дискуссиями относительно территориального устройства новых государств и привёл к росту националистических настроений в обществе. По существу, проблема территориального определения затмила внутриполитические проблемы и сложную внешнеполитическую ситуацию, сложившуюся у границ Закавказья. Сконцентрировавшись на отстаивании своих позиций любой ценой, Армения и Грузия стремились вовлечь в спор «третью» сторону, рассчитывая то на поддержку Добровольческой армии Деникина (Армения), то на Германию (Грузия), то на страны Антанты. Трудно не согласиться с мнением 3. Авалова, полагавшего, что «великим державам до Борчалинского или Алхалакского уезда не было никакого дела в 1919 г.» На его взгляд. и территориальные проблемы, и вопрос суверенизации закавказские государства имели шанс решить на несостоявшейся в ноябре 1918 г. конференции. Он сожалел о том, что не удалось сохранить «Закавказский союз» [Закавказскую федерацию], который, державы Антанты не могли 
игнорировать так же, как «строившиеся государства», поскольку он представлял для них гораздо больший геополитический интерес, чем отдельно взятая Грузия или Армения. Закавказское государственное объединение могло стать транспортным коридором между Европой и Азией а также естественным буфером между Россией и владениями Англии на Востоке. В конечном итоге, его существование делало территориальные проблемы не столь болезненными. Эти факторы были весомыми аргументами в том, чтобы поднимать на конференции вопрос о суверенитете Закавказской федерации, но никак не проблемы «локального уровня» [2, с. 168-172]. Вопрос о признании трёх независимых государств как суверенных, так и не был решён на Парижской конференции. Англия, Франция и США делали расчёт на поддержку армии генерала Деникина и сохранение территориальной целостности России убеждая, в частности, грузинское руководство, присоединиться к нему, а после разгрома большевиков рассчитывать на автономию в составе восстановленного Российского государства $[4$, с. 94].

Декабрьская война 1918 г не привела к разрешению территориальных споров, а «открыла» че- реду конфоликтов 1919-1920 гг. между Арменией и Грузией, в которой активное участие принимали англичане, скорее дестабилизируя ситуацию, чем способствуя её разрешению. Возникшие на конференции в Сан-Ремо в октябре 1920 г «непреодолимые» разногласия по поводу принадлежности «Чорохско-Имерхевского коридора» и проекта железной дороги через Батумскую область, продемонстрировали неспособность армянской и грузинской сторон прийти к соглашению, что привело к отказу стран Антанты в дипломатической поддержке делегаций ввиду отсутствия у сторон «желания договариваться», а также бесперспективности содействию их обороноспособности и дипломатической поддержке в противостоянии с Советской Россией. Фактическое признание независимости этих Закавказских государств, стало ещё одной попыткой Англии и Франции остановить советизацию этого региона. Независимость Армении была признана в январе 1920 года, а уже в декабре она была взята Советами. Признание де-юре независимости Грузии состоялось менее чем за месяц до того, как в ее столицу 25 февраля 1921 г вошли части Красной армии.

\section{Источники и литература}

1. Государственный архив Российской Федерации ГАРФ. Ф. 5881. Оп. 1. Д. 524.

2. Авалов 3. Независимость Грузии в международной политике. 1918-1921. Воспоминания. Очерки. Париж, 1924 $342 \mathrm{c}$

3. Андерсен А. и Парцхаладзе Г. Армяно-Грузинская война 1918 г. и Армяно-Грузинский территориальный вопрос в XX в. URL.: https://www.academia.edu/10382254 (Дата обращения: 5.10.2019).

4. Жордания Н. Моя жизнь. Стэнфорд: Гуверовский институт войны, революции и мира, $1968.130 \mathrm{c}$

5. Документы и материалы по внешней политике Закавказья и Грузии. Тифлис: Типография Правительства Грузинской республики, 1919. 512 с

6. Из истории армяно-грузинских отношений: 1918 г. (пограничные конфлликты; переговоры; война; соглашения). Тифлис: Государственная типография, 1919.142 с.

7. Из книги армянского писателя Мнацаканяна Г. Д. «Разрешение армянского вопроса», опубликованной в 1914 г. // Перинчек М. Армянский вопрос в 120 документах из российских государственных архивов. М: Лаборатория книги, 2011. C. 68-69.

8. Грузия. 1918. 30 октября. №47

9. Грузия. 1918. 9 ноября. №56.

10. Грузия. 1918. 11 ноября. №82.

11. Грузия. 1918. 12 ноября. №58.

12. Грузия. 1918. 21 ноября. №66.

13. Лагвилава Т. И. Политическое и государственное устройство Грузии в 1917-1918 гг. // Восточный архив. 2008 №18. C. 44-49.

14. Мацаберидзе М. Разработка конституции Закавказского Сейма в Национальном Совете Грузии // Кавказ и глобализация. 2008. №2. С. 151-160.

15. Михайлов В. В. К вопросу о политической ситуации в Закавказье на заключительном этапе Первой мировой войны // Вестник Санкт-Петербургского университета. Серия 2. 2006. №4. С. 125-138.

16. Mudros Agreement: Armistice with Turkey (October 30, 1918) // Weimar Germany, 1918/19-1933 URL: http:// germanhistorydocs.ghi-dc.org/pdf/eng/armistice_turk_eng.pdf. (Accessed: 21.11.2019).

17. Stavridis T. The Armenian Question 1918-20: empty promises, survival and Soviet absorption URL: https://www. researchgate.net/publication/279556219_The_Armenian_Question_1918-20 (Accessed: 21.11.2019).

\section{References}

1. State archive of Russian Federation. F. 5881. Inv. 1. D. 524 (In Russian)

2. Avalov Z. Nezavisimost' Gruzii v mezhdunarodnoj politike. 1918-1921. Vospominanija. Ocherki (Georgia's independence in international politicy. 1918-1921. Memories. Essays). Paris, 1924. 342 p. (In Russian)

3. Andersen A., Parchaladze G. Armjano-Gruzinskaja vojna $1918 \mathrm{~g}$. i Armjano-Gruzinskij territorial'nyj vopros v XX v. (The Armenian-Georgian War of 1918 and the Armenian-Georgian Territorial Question in the 20th Century). URL.: https:/(www. academia.edu/10382254 (Accessed: 5.10.2019). (In Russian)

4. Zhordanija N. Moja zhizn' (My Life). Stjenford: Hoover Institution on War, Revolution and Peace publ., 1968. 130 p (In Russian) 
5. Dokumenty i materialy po vneshnej politike Zakavkaz'ja i Gruzii (Documents and materials on the foreign policy of Transcaucasia and Georgia). Tiflis: Georgian Government Printing House, 1919. 512 p. (In Russian)

6. Iz istorii armjano-gruzinskih otnoshenij: $1918 \mathrm{~g}$. (pogranichnye konflikty; peregovory; vojna; soglashenija) (From the history of Armenian-Georgian relations: 1918 (border conflicts; negotiations; war, agreements). Tiflis: State Printing House 1919. 142 p. (In Russian)

7. Iz knigi armjanskogo pisatelja Mnacakanjana G. D. «Razreshenie armjanskogo voprosa», opublikovannoj v $1914 \mathrm{~g}$ (From the book of the Armenian writer Mnatsakanyan G. D. "Solution of the Armenian Question" published in 1914) II Perinchek, M. Armjanskij vopros v 120 dokumentah iz rossijskih gosudarstvennyh arhivov. Moscow: Laboratorija knigi, 2011 256 p. (In Russian)

8. Gruzija. October 30, 1918. No. 47 (In Russian)

9. Gruzija. November 9. 1918. No. 56 (In Russian)

10. Gruzja. November 11.1918. No. 82 (In Russian)

11. Gruzija. November 12. 1918. No. 58 (In Russian)

12. Gruzija. November 21.1918. No. 66 (In Russian)

13. Lagvilava T. I. Politicheskoe i gosudarstvennoe ustrojstvo Gruzii v 1917-1918 gg. (Political and state structure of Georgia in 1917-1918) // Vostochnyj arhiv.2008. No.18. P. 44-49. (In Russian)

14. Macaberidze M. Razrabotka konstitucii Zakavkazskogo Sejma v Nacional'nom Sovete Gruzii (Development of the constitution of the Transcaucasian Sejm in the National Council of Georgia) // Kavkaz i globalizacija. 2008. No. 2. P. 151-160. (In Russian)

15. Mihajlov V. V. K voprosu o politicheskoj situacii v Zakavkaz'e na zakljuchitel'nom jetape Pervoj mirovoj vojny (On political situation in Transcaucasia at the final stage of World War I) // Vestnik Sankt-Peterburgskogo universiteta. Seria 2. 2006. No. 4. P. 125-138. (In Russian)

16. Mudros Agreement: Armistice with Turkey (October 30, 1918) // Weimar Germany, 1918/19-1933 URL: http:// germanhistorydocs.ghi-dc.org/pdf/eng/armistice_turk_eng.pdf. (Accessed: 21.11.2019).

17. Stavridis T. The Armenian Question 1918-20: empty promises, survival and Soviet absorption URL: https://www. researchgate.net/publication/279556219_The_Armenian_Question_1918-20 (Accessed: 21.11.2019).

\section{Сведения об авторах}

Величко Людмила Николаевна - кандидат исторических наук, доцент кафедры зарубежной истории, политологии и международных отношений гуманитарного института Северо-Кавказского федерального университета (Ставрополь) / ludku@yandex.ru

Амбарцумян Каринэ Размиковна - кандидат исторических наук, доцент кафедры зарубежной истории, политологии и международных отношений гуманитарного института Северо-Кавказский федеральный университет (Ставрополь) / karina-best21@mail.ru

\section{Information about the authors}

Velichko Ludmila - PhD in Historical Sciences, Associate Professor, Foreign History, Political Science and Foreign Affairs Department, Institute of Humanities, North-Caucasus Federal University (Stavropol) / ludku@ yandex.ru

Ambartsumyan Karine - PhD in History, Associate Professor, Chair of Foreign History, Political Science and International Relations, North Caucasus Federal University (Stavropol) / karina-best21@mail.ru 